NBER WORKING PAPER SERIES

\title{
MOTIVATING EMPLOYEE-OWNERS IN ESOP FIRMS: HUMAN RESOURCE POLICIES AND COMPANY PERFORMANCE
}

\author{
Douglas Kruse \\ Richard Freeman \\ Joseph Blasi \\ Robert Buchele \\ Adria Scharf \\ Loren Rodgers \\ Chris Mackin \\ Working Paper 10177 \\ http://www.nber.org/papers/w10177
}

\author{
NATIONAL BUREAU OF ECONOMIC RESEARCH \\ 1050 Massachusetts Avenue \\ Cambridge, MA 02138
}

December 2003

This paper is part of the National Bureau of Economic Research's Shared Capitalism Research Project, funded by the Russell Sage and Rockefeller Foundations. We appreciate the useful comments of participants at an Industrial Relations Research Association session in January 2003. Amy Smith-Boden provided valuable assistance in helping conduct and analyze company surveys.

The views expressed herein are those of the authors and not necessarily those of the National Bureau of Economic Research.

(C2003 by Douglas Kruse, Richard Freeman, Joseph Blasi, Robert Buchele, Adria Scharf, Loren Rodgers, and Chris Mackin. All rights reserved. Short sections of text, not to exceed two paragraphs, may be quoted without explicit permission provided that full credit, including $(\mathbb{C}$ notice, is given to the source. 
Motivating Employee-Owners in ESOP Firms: Human Resource Policies and Company Performance Douglas Kruse, Richard Freeman, Joseph Blasi, Robert Buchele, Adria Scharf, Loren Rodgers, and Chris Mackin

NBER Working Paper No. 10177

December 2003

JEL No. J330, J540

\section{ABSTRACT}

What enables some employee ownership firms to overcome the free rider problem and motivate employees to improve performance? This study analyzes the role of human resource policies in the performance of employee ownership companies, using employee survey data from 14 companies and a national sample of employee-owners. Between-firm comparisons of 11 ESOP firms show that an index of human resource policies, nominally controlled by management, is positively related to employee reports of co-worker performance and other good workplace outcomes (including perceptions of fairness, good supervision, and worker input and influence). Within-firm comparisons in three ESOP firms, and exploratory results from a national survey, show that employee-owners who participate in employee involvement committees are more likely to exert peer pressure on shirking co-workers. We conclude that an understanding of how and when employee ownership works successfully requires a three-pronged analysis of: 1) the incentives that ownership gives; 2) the participative mechanisms available to workers to act on those incentives; and 3) the corporate culture that battles against tendencies to free ride.

\author{
Douglas Kruse \\ School of Management and Labor Relations \\ Rutgers University \\ 94 Rockafeller Road \\ Piscataway, NJ 08854 \\ and NBER \\ dkruse@rci.rutgers.edu \\ Richard Freeman \\ NBER \\ 1050 Massachusetts Avenue \\ Cambridge, MA 02138 \\ freeman@nber.org \\ Joseph Blasi \\ School of Management and Labor Relations \\ Rutgers University \\ 94 Rockafeller Road \\ Piscataway, NJ 08854 \\ jrbru@hotmail.com
}

Robert Buchele

Department of Economics

Smith College

Northampton, MA 01096

rbuchele@email.smit.edu

Adria Scharf

Sociology Department

University of Washington

Box 353340

Seattle, WA 98195-3340

ascharf@u.washington.edu

Loren Rodgers

Ownership Associates, Inc.

122 Mt. Auburn Street

Cambridge, MA 02138

1r@ownershipassociates.com

Chris Mackin

Ownership Associates, Inc.

122 Mt. Auburn Street

Cambridge, MA 02138

cm@ownershipassociates.com 
Over one-fifth of U.S. private-sector employees - 24 million workers - own stock in their own companies. Eight million participate in Employee Stock Ownership Plans (ESOPs) (Blasi, Kruse, and Bernstein 2003: 249). The growth of ESOPs over the past 25 years is part of a general growth in compensation arrangements linking worker pay to company performance, including profit sharing, gain-sharing, and broad-based stock options in addition to the various methods of employee ownership (Kruse 1993; Freeman and Dube 2000; Sesil et al 2002, Blasi, Kruse, and Bernstein 2003). Existing research shows that employee ownership firms tend to match or exceed the performance of other similar firms on average (Kruse and Blasi 1997; Blasi, Kruse, and Bernstein 2003: 153-184), but with considerable dispersion of outcomes. The bankruptcy of United Airlines highlights that employee ownership can fail to deliver on its promises in some circumstances (Mackin 2002), while the continued success of firms like Science Applications International Corporation (a Fortune 500 research and engineering company with multiple forms of employee ownership and profit sharing), and the centrality of employee ownership to firms like Microsoft and Cisco Systems, show that ownership can produce long term growth in highly competitive technological industries.

The dispersion of outcomes among employee-owned firms indicates that there is much to learn about the ways in which employee ownership can affect firm performance. In this chapter we use new data to analyze how policies in ESOP companies may help to combat free riding behavior and increase firm performance. Our data are particularly well-suited to explore this issue: one dataset includes employee surveys matched to information on company policies in ESOP firms, while the other two datasets provide the first direct measures of mutual monitoring among employee-owners. This paper is organized as follows. The next two sections review theory and literature on this topic and develop our hypotheses, followed by a brief introduction 
to our three datasets. The first dataset uses between-firm comparisons to examine human resource policies and employee-rated performance using employee surveys in 11 ESOP companies. Following a validation of the employee-rated performance measures, we use regression analysis to see how human resource policies help predict firm performance and other important workplace outcomes. The second dataset presents within-firm comparisons using employee surveys in three ESOP companies, seeing how productivity-enhancing peer pressure is related to employee involvement and training. Finally, we present preliminary results from a third dataset, seeing how peer pressure is related to employee involvement in a national survey of employee-owners in the United States. A summary of the main results and our interpretation is in the conclusion.

\section{Theory and Prior Literature}

In principle, by tying worker pay more closely to firm performance and involving workers in decision-making, employee ownership arrangements can help reduce the principalagent problem in the workplace and increase performance. The most common theoretical objection to positive effects of employee ownership and other group incentive plans is the "free rider" or " $1 / \mathrm{N}$ " problem, which arises due to the weak link between an individual's performance and financial payoff as the workgroup grows larger (if there are $\mathrm{N}$ workers, an individual will get on average only $1 / \mathrm{N}$ of the extra surplus that he or she generates). As standard economic analysis provides no way to resolve the free rider problem, many researchers agree with Weitzman and Kruse that "something more may be needed - something akin to developing a corporate culture that emphasizes company spirit, promotes group cooperation, encourages social enforcement mechanisms, and so forth" (1990: 100). A three-pronged combination of i) incentives, which must be sufficiently meaningful to workers to motivate them; ii) participation, 
which must be sufficiently meaningful for workers to make critical decisions; and iii) a workplace environment or company ethos that resolves, or at least diminishes, the free rider problem appears to be the key to improving performance through employee ownership.

Econometric studies of employee ownership and participation compare firms with different ownership and incentive structures (ownership through pension plans such ESOPs, profit-sharing, broad-based stock options, worker cooperatives, and direct stock ownership) or different participative mechanisms (employee involvement committees, teams, etc) to firms lacking these systems. Most of the studies rely on administrative or company data, leaving to case investigations analysis of how an ownership or participation scheme works in practice. Meta-analyses estimate that the average increase in productivity associated with ESOP adoption is between $4 \%$ and $5 \%$, and give comparable effects for other forms of ownership incentive structures. ${ }^{1}$ But around the average effect is a wide band of outcomes that makes it clear that giving employees an ownership stake is by no means a cure-all to company or workplace problems.

Consistent with this, studies that compare employee attitudes and self-assessed work behavior under employee ownership give a mixed picture (Kruse and Blasi, 1997; Kruse, 1999, 2002). Several studies find higher satisfaction, commitment, and motivation among employeeowners, but others find no significant differences between owners and non-owners, or before and after an employee buyout. Most studies find that organizational commitment and identification

${ }^{1}$ There have been 32 large-sample studies on firm performance under employee ownership (Kruse and Blasi 1997; Kruse 1999). While many make cross-sectional comparisons between firms with and without plans, some compare firms before and after the adoption of such plans, and some look within firms to measure the effects of different features. While the majority of studies do not establish a statistically significant positive link between employee ownership and performance, meta-analyses strongly point toward a significant positive link overall (there are far more positive results than would be expected if there is in fact no true relationship). These positive results also generally appear in research 
are higher under employee ownership, but have results that vary from favorable to neutral on job satisfaction, motivation, and such important forms of behavior as turnover, absenteeism, grievances, tardiness, and injuries.

Productivity studies rarely link employee reports on how ownership plans actually work to company output, in part because employee surveys lack the quantitative output data necessary for such a productivity analysis. Employees in worker owned and participative firms report that their firms perform better than do employees in other firms (Freeman and Dube 2000), but the workers may not be giving a sufficiently accurate assessment of their firm's actual performance. It is only by combining evidence from workers and firms - matched employee-employer data files - that we are likely to make progress in understanding what makes some ownership plans work while others fail, and thus to explain the diversity of outcomes from companies choosing at least nominally similar ownership structures. ${ }^{2}$

\section{Hypotheses: Complementarity and Three Prongs}

What might explain the variation in the employee-reported measures of employee work activity among employee owned firms? Does the historical genesis of ownership affect outcomes? Do employee-owned firms adopt different human resource policies with ensuing differential effects on outcomes?

We offer two hypotheses to explain the variation in employee-reported work effort. The

on profit-sharing and gain-sharing plans (Bullock and Tubbs 1990; Kruse 1993; Collins 1998: 16-17).

${ }^{2}$ Even matched data will not resolve some problems in interpreting results. There may be selection bias in the firms that adopt these plans or workers who work under them, although existing work does not support the notion that selectivity explains results. Studies that adjust for the potential endogeneity of employee ownership find little impact. Studies on the types of workers who choose to work in employee ownership and profit-sharing companies indicate that both high and low performers tend to avoid pay plans tied to group performance; average worker quality is not very different under these plans, so that issues of worker quality are not likely to bias the firm-based estimates. Still, absent a genuine experiment, there will always be some uncertainty about whether results generalize to firms that 
first is the "complementarity hypothesis" that greater participation/influence in decisions, in addition to the economic incentives of an ownership stake per se, are necessary to generate productive employee attitudes and behavior beyond those in other firms (Ben-Ner and Jones 1995). The logic for the complementarity of participation and incentives is impeccable. Why should employee ownership without participation have a substantial effect on worker effort if workers have no way to respond to the incentives of ownership? Similarly, why should opportunities to participate without incentives - say through teams of quality circles, where there is no economic payoff to additional effort - generate the types of behavior that will substantially improve company outcomes? As Ben-Ner and Jones (1995) argue, both ownership without participation, and participation without ownership, can even decrease performance by frustrating worker expectations and increasing conflict. Firms need incentives and opportunities working together for employee ownership or any other form of organization to yield improved performance. There is evidence that employee ownership and participation are positively correlated (Freeman and Dube 2000; Conyon and Freeman 2001), so that employee-owned firms are more likely to have participative structures than other firms, and conversely. But the evidence that this produces superior outcomes is less clear. Freeman and Dube found that employee reports of productive behaviors were higher in companies that combined employee ownership or profit sharing with employee participation in decision-making and concluded that "the impact of compensation practices appears to be contingent on such decision making structures" (2000: 18). But, lacking matched firm data, they had no evidence that the employee reports translate into actual superior company performance.

The "three prong hypothesis" is that complementarity of incentives and participation is

have not chosen employee ownership. 
itself not enough to produce the best outcomes. This is because the opportunity to free ride on the efforts of others can undermine even the best ownership incentive. Firms, or workers, must do something more to prevent free riding behavior from destroying employee morale and the potential of an ownership incentive system. They must set in motion forces that lead employees to view themselves as critical contributors to output even though each individual's contribution is modest, much as democracies must motivate voters to go the polls even though it is rare that any single vote determines any election. Economists understand less about the ways in which employee-owned organizations and their employees or other firms accomplish this than they understand responses to individual incentives.

Human resource policies may be a part of the "something more" that establishes a cooperative solution. These policies include not just worker participation in decisions, but also other policies that draw more fully on worker skills and information about the work process, and increase workers' sense of participation, security, and fair treatment. Such policies in employee ownership companies may help to create a more cooperative culture that leads to greater effort, commitment, worker co-monitoring (reducing central monitoring by supervisors), and information sharing. A growing number of studies of human resource practices show that innovative human resource practices can improve business productivity, primarily through the use of systems of related work practices designed to enhance worker participation and flexibility in the design of work and decentralization of managerial tasks and responsibilities (Ichniowski, et al 1996: 322).

Ichniowski et al (1996), Appelbaum et al. (2000), and Becker, Huselid, and Ulrich (2001) all find that new systems of participatory work practices have substantial effects on business performance while isolated changes in individual work practices do not generally improve performance. These studies relate to diverse firms, rather than the employee ownership firms on 
which we focus. The three-pronged hypothesis is that these policies and practices have larger effects on employee owned firms than on firms that lack the ownership incentive and accompanying modes of participation. With our data, however, we can only explore the possible link between these policies and worker efforts among the employee-owned firms.

\section{Data}

This paper uses survey data from 14 ESOP companies to examine the factors that affect the differential impact of employee ownership on productivity and work behavior. The surveys were conducted at different periods of time by Ownership Associates, a consulting firm ${ }^{3}$, and by our research team. The Ownership Associates (OA) survey (Ownership Culture Survey) covers employees and managers in eleven ESOP companies over the period 1996-2002. The OA survey asked employees about their views and attitudes toward various aspects of their workplace, including the effort employees gave, their level of involvement in decision making, and their feelings about ownership of the firm. The managers filled out a survey on human resource policies, firm performance, and ESOP characteristics. ${ }^{4}$ The firms in this survey are relatively small: the number of employees range from 27 to 1800, with a mean of 396 and median of 181. Seven of the companies had between 100 and 300 employees. There are a total of 2139 survey respondents from the 11 companies, giving a response rate for workers of $71 \%$ across all companies. Because the survey obtained both worker reports on participation, effort, and ownership, and company data on actual outcomes, these data provide a check on the extent to which worker reports of effort show up in actual firm performance.

\footnotetext{
${ }^{3}$ Ownership Associates, Inc. is a Cambridge, MA consulting firm "providing strategic and technical advice to groups exploring employee ownership." See www.ownershipassociates.com ${ }^{4}$ Most of the companies in the Ownership Associates survey converted to employee ownership when the principal owner of the firm retired. None of the firms were having serious performance difficulties before conversion and none required workers to give concessions for ownership.
} 
Our second data set contains information on employees in three firms that the NBER's shared capitalism research project surveyed in 2001 and 2002. Here the focus is on individual variation in the ways workers try to prevent free riding behavior from undoing the potential positive effects of ownership and participation. In particular, we ask workers how they would respond to employees who are not carrying their weight in the firm and relate their responses to the position of the employees in participative structures.

These samples are small and thus give results that should be viewed only as suggestive. The National Opinion Research Center (NORC) has completed the 2002 General Social Survey using questions that we devised analogous to those in the current study. This survey has both a representative sample of workers and data that match workers with firms. Some of the questions on this survey mimic those on our company surveys. We present initial results using data on employee-owners in the national survey, providing a check on the company survey results.

Despite the comparisons with national data on some of the results, some readers may worry that our samples are overly selective, and could produce results that do not generalize to other ESOP companies, much less to firms more generally. But the OA sample is well-suited to assess the variation in outcomes among firms with a similar ownership structure, and the NBER shared capitalism sample is well-suited to examine the variation of workers within them. On the one side, by basing our analysis on comparisons within these groups, we potentially avoid errors in interpretation due to selectivity. On the other side, a set of fairly similar firms with comparable ownership structure provides just the right sample to assess variation within the employee ownership structure.

\section{Variation in Employee-reported and Company Performance Measures}


The starting point for our analysis is the variation in outcomes among employee-owned firms. Table 1 shows wide variation in employee-reported measures of work outcomes in the 11 firm OA sample; wide variation in objective company measures of outcomes; and, critical for our research strategy, a substantive positive relation between the two measures. The top half of Table 1 gives the mean and standard deviation of employee responses to 6 statements about work activity at the firm on a seven point scale. It shows whether employees agree with 4 positive statements_- "People at [OurCo] work hard ... care about meeting customer needs ... are willing to make sacrifices to help co-workers; are very committed to the company and its future"-as well as with 2 negative statements — “As long as jobs are secure, company performance is unimportant ... and [OurCo] employees work less when supervisors are not watching." ${ }^{5}$ In addition, we have formed summary indices of the positive statements, and of all six statements, reverse coding the negative statements so that the summary statistic reflects positive reports overall. While the data show considerable variation in the responses in the entire sample, indicating that employees have a wide range of views, the general pattern is for workers to agree with the more positive statements. The critical statistics are the F-statistics in column 4, which test whether there are consistent firm-level differences within this variation. These statistics show sizable firm differences, which increase in significance as we form the summary statistics. The implication is that workers at different ESOP firms have consistently different views of worker performance at their firms.

The bottom of Table 1 gives the firm-reported performance measures. Because the firms are in different industries, we adjusted the reported measures for industry levels or trends over the past three years, using data on public companies from Standard and Poor's Compustat. Since

\footnotetext{
${ }^{5}$ The two negative statements were asked at only 8 of the 11 companies, so the sample size is smaller.
} 
the ESOP companies are all privately-held and relatively small companies, they tend to have lower productivity than the larger Standard and Poor's firms (thus the negative value for average $\ln ($ sales/employee)). In addition, their employment and sales growth is lower than the average in the industry in which they operate. At the same time, their profit margin and stock price growth exceeded industry averages. What is important for our purposes, however, is not the difference between these firms and others in their given sector, but the variation among the firms themselves (relative to their given sector). The standard deviation of each of the industryadjusted objective company performance measures exceeds the absolute value of the mean of all but one of the measures, implying a huge disparity in outcomes.

Are the employee reports of productive behaviors related to the objective firm-reported measures? Since the worker-reported measures and the objective company measures relate to different aspects of performance, we expect some variation even if the employee reports are accurate. The correlation between company performance and "people at our company work hard," for instance, need not be high even if workers report correctly on work effort, since there are many influences upon company performance apart from employee behaviors. Nonetheless to the extent that employee behaviors influence performance, there should be a positive link between reported productive behaviors and company performance if the employee reports are meaningful. Columns 4-6 of Table 1 report firm-level correlations between the objective company measures and the average within-company scores of three employee-reported measures (People at [OurCo] work hard," which has the greatest face validity among the employee measures, plus the 4-item and a 6-item summary indices. ${ }^{6}$ ) All of the correlations are positive,

\footnotetext{
6 The alpha scores, measuring the correlation between the index and the underlying factor, are .75 and .78 , respectively.
} 
though they vary greatly in magnitude. The highest correlations are with the profit margin $(.582$ to .630) and 3-year employment growth (.481 to .621). Correlations with productivity levels (measured as $\ln ($ sales/employee)) vary (.019 to .337$)$, while correlations with productivity growth over the past three years show a consistent pattern (.328 to .373$)$. While the sample of firms is too small to make any strong statistical statement, the consistent positive correlations provide some validation for the employee-reported measures.

\section{Specific human resource policies}

As noted earlier, human resource policies may be key to establishing a cooperative culture in employee ownership firms. Table 2 shows the diversity of human resource policies among the eleven OA companies. Column 1 reports the percentage of practices across the companies, while column 2 reports the percentage weighted by employment. Only two firms use techniques that clearly increase involvement in job-level decisions (quality circles and autonomous workgroups), though seven firms have employee task forces, five have employee involvement in new hires, and three have employee representation on the board of directors. Summing these involvement activities, the "EI index" in the table shows that the average company in the sample used only 1.55 of these five techniques.

The survey also asked about nine methods of sharing information with employees. The most common methods are new employee orientations and regular meetings at the department or workgroup level (each used by ten firms), while the least popular is an intranet (used by three firms). On average firms use 6.18 of these methods, as measured by the "Information index." The company survey asked about several other policies. All but one of the eleven firms have a 401(k) plan, while only three have a deferred profit-sharing or other type of defined contribution pension, and none have defined benefit pensions. While none of the eleven firms is 
unionized, five of them have formal grievance procedures, which can help increase employees' sense that they will be treated fairly. Four of the firms report labor-management training to enhance employee skills and workplace relations. Complementing the methods to share information with employees, seven companies report administering employee surveys to collect employee views, while three report having suggestion systems. Ten of the eleven companies report some type of cash profit sharing or bonus system, while half of these report that the bonus is at least partly tied to individual performance.

Table 2 also reports on several variables connected to the ESOP. On average, companies contributed close to $10 \%$ of their total payroll cost to the ESOP in the previous year, with percentages ranging from $3 \%$ to $20 \%$. The percent of the company owned by the ESOP averages $54.2 \%$, ranging from $9 \%$ to $100 \%$. More important potentially for worker incentives, the ESOP value per employee averages $\$ 41,988$, ranging from $\$ 3,200$ to $\$ 181,052$. Several studies indicate that such wealth tends to come on top of, rather than in place of, other pension plans, wages, and benefits in ESOP companies (reviewed in Kruse 2002). Seven of the companies reported a performance-related reason for adoption of the ESOP, which will be used to help control for selection bias that may contaminate the results (since companies reporting performance-related reasons for adoption were probably more likely to have performance difficulties prior to adoption). ${ }^{7}$

There are far more human resource policies than companies in the OA survey, which makes it impossible to sort out the independent effects of policies. To deal with this problem, we

\footnotetext{
7 Six companies checked the reason "To encourage employees to think like owners," four checked "To improve productivity," and six checked "To retain or recruit employees." The other listed reasons for ESOP adoption, which can overlap, were "to purchase stock from an owner" (6 companies), "to raise capital for the company" ( 1 company), "for tax advantages" (5 companies), and "as an employee benefit" (7 companies).
} 
added together seven of the policies to form the HR index reported at the bottom of the table. The index assigns one point each for being above the median on 1) the EI index, 2) the information index, and 3) the percent of pay contributed to the ESOP; and one point each for having 4) a pension other than $401(\mathrm{k}), 5)$ a formal grievance procedure, 6) labor-management training, and 7) employee surveys. Factor analysis and assessment of alpha scores showed that these were the policies that best fit together, appearing to measure the intensity of a common approach to human resources. The average score on the 0-7 HR index, as shown in Table 2, is $3.55^{8}$

\section{HR Policies and Performance}

Are the HR variables linked to performance? Table 3 reports regressions of the three employee-reported performance measures ("People at [OurCo] work hard," and performance indices 1 and 2 from Table 2) on the HR index, the use of individual bonuses, suggestion systems, and percent of company owned by the ESOP. Whereas the HR index relates to group incentives and participation, individual bonuses and a suggestion system reflect individual incentives and are only weakly related to other items in the index. In addition, columns 2-3, 5-6, and 8-9 include a variable for whether the firm introduced the ESOP because of economic performance concerns, and columns 3, 6, and 9 include a variable representing the subjective sense of ownership. For six of the companies we also had information on employees' age, gender, and broad job classification, but regressions including these variables for this subset showed little difference in the main variables of interest, and the table reports the results for the

8 The seven policies were added together to form this index. The alpha score is .85 . The $401(\mathrm{k})$, bonus, and suggestion system variables had low positive correlations (less than 0.40 ) with the other items in the index, while bonuses based on individual performance had a negative correlation $(-0.40)$ with the other items in the index, indicating that these variables are not closely related to the other items in the HR index and are unlikely to be part of a common factor. 
total sample absent those demographic variables. The regressions account for correlated errors among employees in the same company. The results from ordered probit regressions were very similar to those reported here.

The results in Table 3 show that the HR index is positively related to worker-reported work effort, and significantly different from zero in seven of the nine regressions. They also show a positive relation between individual bonuses and the outcome variables and a negative relation between the use of a suggestion system and outcomes. ${ }^{9}$ We estimate that an increase in the HR index of one standard deviation (1.97, from Table 2) increases the score on "People at [OurCo] work hard" by about .2, and increase the scores on performance indices 1 and 2 by about .8 and 1.2, respectively. These represent increases of about $15-20 \%$ of a standard deviation in the performance measures.

The percent of company owned by the ESOP is not a significant predictor of the performance measures. The size of an individual's ownership stake may provide a better measure of the ownership incentive facing an employee, but similar results obtain when average ownership stake per employee is used as a predictor. This supports the idea that it is not ownership per se, but the cooperative culture that can be fostered by employee ownership, that drives better workplace performance in ESOP firms.

Are these coefficients affected by selection bias due to the types of firms that implemented HR policies? Firms with low productivity may be more likely to adopt HR policies to enhance performance, which would cause a downward bias in the HR index coefficient. One way to partially address this possibility is to use information on the reasons for ESOP adoption.

\footnotetext{
${ }^{9}$ Suggestion systems are often nothing more than a "suggestion box" on the wall, which are so mundane that they don't indicate much about HR policy. It is possible that formal suggestion systems are even a substitute for meaningful involvement.
} 
As noted earlier, seven of the firms listed a performance-related reason for ESOP adoption, which may indicate a higher likelihood of pre-existing performance problems. Inclusion of this variable in regressions 2,5 , and 8 does not reduce the effect of the HR variables on the "people at our company work hard" outcome measure nor on the summary performance index 1 , though it does slightly weaken the link between performance index 2 and the HR index. (We return to discuss regressions 3, 6, and 9 after a description of Table 4.)

\section{HR Policies and Cooperative Solutions}

Do the HR policies affect other workplace outcomes that might make it easier to sustain a high participation/outcome solution against tendencies to free ride?

To answer this question, in Table 4 we examine the link between other worker-reported aspects of the workplace and the HR policies. These "other outcomes" range from variables closely linked to ownership - whether or not employees have a real influence over the direction of the firm, company response to employee suggestions, and encouragement of worker participation in decisions - to relations with co-workers and views of management and supervisors, among others. Table 4 reports coefficients from separate regressions of each of these variables on the HR index. The HR index is positively related to most of these workplace outcomes, although fewer than half of the estimates are significantly different from zero. Significant positive outcomes are most likely in perceptions of fairness, good supervision, and worker input and influence. Apart from being important in themselves, each of these outcomes may be important in company performance (and are in fact correlated with perceptions of better performance). Two results, however, go against expectation. Employee ownership and employee involvement may, as noted, help increase performance by decreasing centralized supervision. Workers with higher scores of the HR index were actually slightly (but not 
significantly) more likely to say that "People feel they are too closely supervised—someone is always checking up on them." While this might indicate that supervision is higher in firms with more HR policies (because managers or fellow employees have a greater stake in ensuring that workers work hard) it may also indicate that workers who are covered by more HR policies do not think they need to be supervised as much, and may somewhat resent the supervision they do receive. This suggests that supervisors and middle managers may have particular problems in adapting to employee ownership plans and other group incentive plans.

A second result that is relevant to company performance concerns feelings of ownership. One of the key questions on the OA survey asks workers "How much do you feel like an owner of this company?" While one might expect that HR policies help create a cooperative culture that leads to or reinforces a sense of ownership in ESOP firms, we instead find that sense of ownership is essentially uncorrelated with the HR policy index. There are two possible explanations. The first is that the feeling of ownership is irrelevant to actual work performance and thus is unaffected by policies designed to improve workplace performance. If this were the case, there would be no correlation between employee feelings of ownership and employee reports on work outcomes. In fact, Table 3 shows a positive correlation between the sense of ownership and our three outcome measures with the inclusion of the nearly independent HR index (columns 3, 6, and 9). The most sensible interpretation of these results is that both ownership and participation enter workers' work effort, but that workers judge their ownership by the actual economic incentives and not by the policies that firms of all sorts use to be "good employers." The implication is that neither the workers nor the researchers should expect a sense of ownership from the standard array of advanced HR policies. To test this notion, we examined the relation between workers' feelings of ownership and two measures of actual ownership - the 
average ESOP value for employees in the firm and the percentage of the company that the ESOP owned. Both of these factors are positively correlated with workers' feelings about ownership (the correlation with $\ln ($ average ESOP value) is .125, and with percent of company owned is .136 , both significant at $\mathrm{p}<.001$ ). How much equity employees actually have would appear to be more important in judging ownership than HR policies that do not affect the ownership stake of workers. It may, however, be the case that much depends on how the policies are presented to workers: a company could talk about participation or information sharing as a policy which is worthwhile in its own right, or as a policy which is tightly linked to employee ownership. It could be this linkage that has an effect on ownership identity, not the policies themselves.

\section{The NBER Sample and Employee Response to Free-Riding}

In 2002 the NBER Shared Capitalism research project undertook a set of surveys of firms with particular employee ownership structures and commissioned NORC to ask a set of questions of a nationally representative sample of workers regarding ownership, participation, and company culture, and to develop a matched employer-employee data set as well. Here we present data from the first three case studies of employee owned firms. These three firms are in the 250-500 employee category, and have an average response rate from workers of $60 \%$. Two of the firms are $100 \%$ employee owned, while the other firm is one-third owned by employees, so these are in the upper tail of ESOP firms in terms of ownership. We concentrate on how employee participation on EI committees and involvement in group decision-making affects responses to free riding behavior.

Table 5 provides descriptive data on our key variables from the surveys in these three firms. The principal question on our survey relating to employee response to free-riding 
behavior is:

If you were to see a fellow employee not working as hard or well as he or she should, how likely would you be to:

Talk directly to the employee

Speak to your supervisor or management

Do nothing

The responses were given on a four point scale, running from (1) not at all likely, to (2) not very likely, to (3) somewhat likely, to (4) very likely. For ease of presentation and to allow for a relatively simple difference-in-difference analysis of the data, we summarize the responses as the mean of the coded answers. The descriptive statistics in the upper panel of Table 5 show that workers at each of the firms were likely to talk directly to the employee or speak to the supervisor, though there is considerable variation among individuals with a standard deviation of about one unit (the difference between two categories). The bottom panel of Table 5 gives three indicators of the role of the worker in the firm: whether the worker served on an employee involvement committee or team or task force; whether the employee received training in the past year and the employee's perceived involvement in three activities: doing their own job; setting goals for their work group or department; and participating in overall company decisions. In company A, where the workers are more skilled, approximately half of the work force serves on EI committees and $60 \%$ received some training. By contrast, in firm B just $29 \%$ serve on some EI committee and $17 \%$ received some training. Company $\mathrm{C}$ has $41 \%$ on an EI committee and $67 \%$ who received some training. In all three firms, workers report having greater involvement in deciding to do their own jobs than in setting goals for their work group, and least involvement in overall company decisions.

Under which of these situations is a worker more likely to intervene actively when they see someone not working up to speed? We expect workers to be more likely to respond against 
free riding when they are involved in a group work activity than when they are in a more individualistic work situation. If this is the case, workers on EI teams should be more prone to actively intervene against free riding than other workers. Similarly, workers who are more involved in setting goals for their work group or department should be more likely to intervene actively than other workers. Do the data show such patterns, and if so, to what extent, if at all, can we interpret them as being causally related to the workers' position in the organization as opposed to some unobserved individual characteristic?

\section{EI committees, involvement in decisions, and response to free-riding}

The evidence in Table 6 shows that workers on EI committees are far more likely to talk directly to the employee and much less likely to do nothing than workers who are not on such committees. The mean score for the response of "talk directly" for workers in company A who are on committees is 2.93 compared to a mean score of 2.21 for those who are not on committees, giving a statistically significant difference of 0.72 in company A. The comparable significant differences in companies $\mathrm{B}$ and $\mathrm{C}$ are 0.50 and 0.46 , respectively. The differences between EI members and other workers in speaking to a supervisor about a worker not doing his or her job are smaller though still significant in two firms, while the differences in doing nothing are significant in the opposite direction for all three firms. These results are consistent with the notion that the position of workers on EI committees leads them to intervene more than other workers when they see someone not doing their job and, most important, to intervene directly to a greater extent than going to a supervisor. The difference between talking to the employee directly and speaking to the supervisor or manager is a substantial 0.36 in company A (0.72$0.36), 0.15$ in company $\mathrm{B}(0.50-0.35)$, and 0.17 in company $\mathrm{C}(0.46-0.29)$. 
It is possible that some of the differences attributed to employee involvement and training in Table 6 are actually due to their positions in the firm. To check for this, we reestimated the differences, controlling for job categories (which range from production jobs to top management) and pay categories (hourly, salaried-nonexempt and salaried-exempt). With these controls, many differences (not reported here) become smaller in absolute value, but there were no sign reversals, and most of the differences remain statistically significant.

Absent a before/after experiment of placing employees on EI committees and seeing how they react to this group responsibility, we probe for causality in the observed relation by comparing worker responses to slackers by participation on committees versus other differences in their work lives. We do this in two ways. First, we contrast the difference in response to free riding between workers serving on EI committees and workers not serving on EI committees to the workers' assessment of their willingness to work hard for the company. We derive this variable from a question: "I am willing to work harder than I have to in order to help the company I work for succeed," which we scaled on a five-point scale, including the neutral response "neither agree nor disagree." Persons on EI committees in all three companies report that they are more likely to work hard than do workers who are not on those committees, but the magnitude of the difference is markedly smaller than the difference in their likelihood of talking directly to the employee who is doing poorly. That is, the EI/non-EI difference in opposing free riding behavior is greater than the personal difference in work effort between EI and non-EI workers.

Second, we compare the difference in responses to free riding between persons with and without EI to the difference in responses between workers who did and did not receive training. Workers given training by the firm are likely to be valued employees, and thus might be 
expected to intervene when other employees are not doing their job. The results in the bottom panel of Table 6 show such a pattern (at least for companies A and C). But once again the training/no training differences are smaller than the EI/non-EI differences in the likelihood of talking to a shirking co-worker, strongly suggesting that EI is playing a positive role.

Our surveys contain multiple other questions from which we can derive differences for comparison with those from the EI committee contrast. All those we have examined show smaller differences than the ones found for the EI committee involvement, which is consistent with the notion that there is a real impact from the role that workers play in organizational decision-making.

Table 7 examines this pattern using a different set of questions. It uses responses to questions about workers' perceived involvement on their own jobs, in setting goals for their work groups, and in overall company decisions, to see whether group activity produces greater worker efforts to police free riding behavior than other forms of involvement. The table gives the average scores of workers on their likelihood of responding to a co-worker who is not doing his or her job right, by their level of perceived involvement in each specified activity. In virtually all cases, workers who are more involved in some activity are more likely to talk directly to employees who are performing poorly, more likely to speak to supervisors, and less likely to do nothing about the poorly performing employee, than employees who feel no sense of involvement in the specified area. These differences are generally maintained in exploratory regressions that control for job category and pay category.

A key question is whether these differences vary by type of involvement. Involvement in workgroup decisions with one's day-to-day co-workers is more likely to generate knowledge of and concern for co-worker performance, which should increase worker willingness to apply peer 
pressure. The data in the table show this pattern. The P-values reflecting the difference in responses among categories compared to a null hypothesis of no difference are markedly smaller for "perceived involvement in setting goals for work group" than for either of the other categories. In companies B and C, there are no significant differences by involvement in one's own job in the likelihood of talking directly to the poor performer compared to highly significant differences by involvement in setting workplace goals.

As a check on these results, we also present data from NORC's 2002 General Social Survey, on which we placed the questions concerning how one would respond to a shirking coworker. Table 8 presents figures comparable to those in Table 7, breaking down the average responses to shirking co-workers according to participation in workplace decisions by employeeowners (using different participation questions than in the case study surveys). The survey found that 265 of the 1134 workers in for-profit firms, or $23.4 \%$, reported owning stock in their companies. As shown in Table 8, the results from this representative sample of employee-owners are very consistent with the results from our case study surveys: those who report greater participation in decisions are significantly more likely to talk to shirking co-workers, and significantly less likely to do nothing. These data provide a useful initial picture of how workers' participation in decision-making in employee ownership firms is associated with their efforts to reduce free riding behavior. In future work we will examine whether employee owners make a greater effort to police poor performance than other workers, whether the proportion of the employee ownership incentive to the worker's salary or overall wealth influences this behavior, and whether serving on an EI committee or being more involved in setting workgroup goals has a greater or lesser effect in an employee-owned enterprise than in another enterprise. 


\section{Conclusion}

Economic theory suggests that, by itself, employee ownership is unlikely to have a large effect on worker effort and performance. Ownership must be combined with employee involvement and other policies that give workers the power to act on the incentives; and employee ownership firms and other organizations that rely on group incentives must battle against the tendency to free ride. Our analysis of variation in worker-reported effort across eleven ESOP firms, and of employee-owners in three ESOP firms and a representative national sample, tends to support the need to combine the incentive of ownership with the involvement of participation. We find significant differences in worker assessment of work effort across ESOP firms, indicating that even in firms with substantial employee ownership, other factors influence outcomes. Relating worker-reported outcomes to their sense of ownership and an index of HR policies shows that ownership and HR policies are both positively linked to employee reports of workplace performance, which is itself related to company performance. Our analysis of employee response to co-workers who are failing to do a good job shows that workers on employee involvement committees or who otherwise report being involved in setting goals for their work group are more likely to talk directly with a non-performing worker and are less likely to do nothing. Conceptually, an understanding of how employee ownership works successfully, or not, requires a three-pronged analysis of: the incentives that ownership gives, the participative mechanisms available to workers to act on those incentives, and incentives/corporate culture that battles against tendencies to free ride. All firms, whether employee owned or not, have to combine these three elements in some fashion to motivate workers to perform as best they can. Employee ownership provides a distinct solution to the incentive problem, but must still deal with the participation and free-riding problems. 


\section{References}

Appelbaum, Eileen, Thomas Bailey, Peter Berg, and Arne Kalleberg. 2000. Manufacturing Advantage: Why High-Performance Work Systems Pay Off. Ithaca, NY: Cornell University Press.

Becker, Brian, Mark Huselid, and Dave Ulrich. 2001. The HR Scorecard: Linking People, Strategy, and Performance. Boston, MA: Harvard Business School Press.

Ben-Ner, Avner, and Derek C. Jones. 1995. "Employee Participation, Ownership, and Productivity: A Theoretical Framework," Industrial Relations 34 (4): 532-54.

Blair, Margaret, Douglas Kruse, and Joseph Blasi. 2000. "Is Employee Ownership an Unstable Form? Or a Stabilizing Force? in Thomas Kochan and Margaret Blair, eds., The New Relationship: Human Capital in the American Corporation. Washington, D.C.: The Brookings Institution.

Blasi, Joseph, Douglas Kruse, and Aaron Bernstein. 2003. In the Company of Owners. New York: Perseus Books.

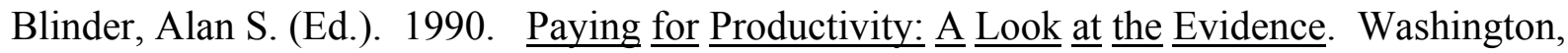
D.C.: Brookings Institution.

Collins, Denis. 1998. Gainsharing and Power: Lessons from Six Scanlon Plans. Ithaca and London: Cornell University Press, ILR Press.

Conyon, Martin J., and Richard Freeman. 2001. "Shared Modes of Compensation and Firm Performance: UK Evidence," Working Paper No. 8448, National Bureau of Economic Research, Cambridge, MA.

Craig B. and J. Pencavel. 1992. "The Behavior of Worker Cooperatives: The Plywood Companies of The Pacific Northwest," American Economic Review, 82, 1083-1105.

-----. 1993. “The Objectives of Worker Cooperatives," Journal of Comparative Economics, Vol. 17(2), June, pp. 288-308.

-----. 1995. "Participation and Productivity: A Comparison of Worker Cooperatives and Conventional Firms in The Plywood Industry," Brookings Papers on Economic Activity, 212-160.

Freeman, Richard, and Arin Dube. 2000. "Shared Compensation Systems and Decision Making in the U.S. Job Market,” Draft, Harvard University Department of Economics.

Freeman, R and Joel Rogers. 1999. What Workers Want. New York: Russell Sage and Cornell University Press. 
Freeman, R, Morris Kleiner, and Sherrie Oster, 1999 “Does Employee Involvement Work?" paper for AEA Meetings, January 2000

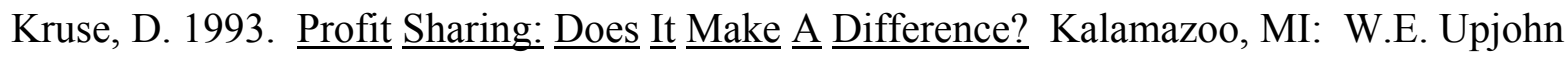
Institute for Employment Research.

-----. 1999. "Economic Democracy or Just Another Risk for Workers? Reviewing the Evidence on Employee Ownership and Profit Sharing," paper delivered at "Democracy, Participation, and Development" conference, Columbia University, April. School of Management and Labor Relations, Rutgers University.

-----. 2002. "Research Evidence on the Prevalence and Effects of Employee Ownership," Journal of Employee Ownership Law and Finance, Vol. 14, No. 4, Fall, pp. 65-90.

-----, and Joseph Blasi. 1997. "Employee Ownership, Employee Attitudes, and Firm Performance: A Review of the Evidence," in The Human Resources Management Handbook, Part 1. Edited by David Lewin, Daniel J.B. Mitchell, and Mahmood A. Zaidi. Greenwich, CT.: JAI Press.

Levine, David. 1995. Re-inventing the Workplace: How Both Business and Employees Can Win

Logue, John, and Jacquelyn Yates. 2001. The real world of employee ownership. Ithaca, N.Y.; London: ILR Press.

Mackin, Christopher. 2002. “United It Was Not,” unpublished manuscript. Cambridge, MA www.ownershipassociates.com

Sesil, James, Maya Kroumova, Joseph Blasi, and Douglas Kruse. 2002. "Broad-based Employee Stock Options in High-Technology Firms: Company Performance Effects," British Journal of Industrial Relations, Vol. 40, No. 2, June, pp. 273-294. 
TABLE 1: Employee-reported and Company Performance Measures

\begin{tabular}{|c|c|c|c|c|c|c|c|}
\hline & $\begin{array}{l}\text { Mean } \\
(1) \\
\end{array}$ & $\begin{array}{l}\text { (s.d.) } \\
(2) \\
\end{array}$ & $\begin{array}{l}n \\
(3)\end{array}$ & $\begin{array}{l}\text { F-stat. } \\
\text { for co. } \\
\text { differences^ } \\
\quad(4) \\
\end{array}$ & $\begin{array}{l}\text { Correlation of ob } \\
\text { average within } \\
\text { "People at OurCo } \\
\text { work hard" } \\
(5)\end{array}$ & $\begin{array}{l}\text { jective measure } \\
\text {-company score } \\
\text { Performance } \\
\text { Index1 } \\
(6) \\
\end{array}$ & $\begin{array}{l}\text { with } \\
\text { on: } \\
\text { Performance } \\
\quad \text { Index2 } \\
\quad(7)\end{array}$ \\
\hline \multicolumn{8}{|l|}{ EMPLOYEE-REPORTED MEASURES ${ }^{\wedge \wedge}$} \\
\hline $\begin{array}{l}\text { "People at [OurCo] work hard." } \\
\text { "People at [OurCo] care about meeting our customers' } \\
\text { needs." }\end{array}$ & $\begin{array}{l}5.66 \\
5.68\end{array}$ & $\begin{array}{l}(1.37) \\
(1.29)\end{array}$ & 2139 & $\begin{array}{l}24.43 \\
25.44\end{array}$ & & & \\
\hline $\begin{array}{l}\text { "People at this company are willing to make } \\
\text { sacrifices to help co-workers." }\end{array}$ & 4.65 & $(1.64)$ & 2139 & 37.24 & & & \\
\hline $\begin{array}{l}\text { "Employees at [OurCo] are very committed to the } \\
\text { company and its future." } \\
\text { Performance index } 1 \text { (sum of above four) }\end{array}$ & $\begin{array}{l}4.81 \\
20.8\end{array}$ & $\begin{array}{l}(1.51) \\
(4.43)\end{array}$ & $\begin{array}{l}2139 \\
2139\end{array}$ & $\begin{array}{l}19.58 \\
42.35\end{array}$ & & & \\
\hline $\begin{array}{l}\text { "As long as their jobs are secure, company performance } \\
\text { is unimportant to people at [OurCo]." }\end{array}$ & 3.08 & $(1.70)$ & 1690 & 21.32 & & & \\
\hline $\begin{array}{l}\text { "[OurCo] employees work less when supervisors } \\
\text { are not watching." } \\
\text { Performance index2 (sum of above six, last two } \\
\text { reverse-scored) }\end{array}$ & 30.49 & $\begin{array}{l}(1.92) \\
(6.49)\end{array}$ & $\begin{array}{l}1693 \\
1686\end{array}$ & $\begin{array}{l}21.18 \\
55.76\end{array}$ & & & \\
\hline \multicolumn{8}{|l|}{ 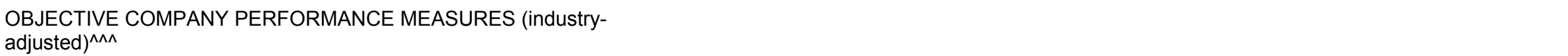 } \\
\hline Avg. In(sales/employee) over past 3 years & -0.425 & $(0.682)$ & 10 & & 0.337 & 0.135 & 0.019 \\
\hline Avg. profit margin over past 3 years & 0.319 & $(0.309)$ & 9 & & 0.630 & 0.631 & 0.582 \\
\hline Employment growth over past 3 years (pct.) & -0.086 & $(0.355)$ & 10 & & 0.621 & 0.561 & 0.481 \\
\hline Sales growth over past 3 years (pct.) & -0.200 & (0.315) & 10 & & 0.495 & 0.416 & 0.407 \\
\hline Stock price growth over past 3 years (pct.) & 0.190 & $(0.246)$ & 9 & & 0.189 & 0.147 & 0.352 \\
\hline Ln(sales/employee) growth over past 3 years & -0.080 & $(0.117)$ & 10 & & 0.373 & 0.328 & 0.328 \\
\hline
\end{tabular}

${ }^{\wedge} \mathrm{F}$-statistic for test of null hypothesis that employee-reported measures do not differ among the 11 firms, rejected in every case at the $p<.0001$ level.

$\wedge^{\wedge}$ All employee-reported measures use 1-7 scale, with $1=$ "strongly disagree," $4="$ neutral," and $7=$ "strongly agree."

$\wedge \wedge \wedge$ For the industry adjustment, average values for public firms in the same size class and 2-digit SIC were subtracted from each company's score. 
TABLE 2: Human Resource Policies

\begin{tabular}{|c|c|c|c|c|}
\hline & $\begin{array}{l}\text { Among } \\
\text { firms } \\
(1)\end{array}$ & $\begin{array}{c}\text { (s.d.) } \\
(2)\end{array}$ & $\begin{array}{c}\text { Among all } \\
\text { employees }^{\wedge} \\
(3)\end{array}$ & $\begin{array}{c}(s . d .) \\
(4)\end{array}$ \\
\hline Sample size & 11 & & 2139 & \\
\hline \multicolumn{5}{|l|}{ EMPLOYEE INVOLVEMENT } \\
\hline Quality circles & $9.1 \%$ & & $5.1 \%$ & \\
\hline Employee task forces & $63.6 \%$ & & $75.6 \%$ & \\
\hline Autonomous work groups & $9.1 \%$ & & $5.3 \%$ & \\
\hline Employee involvement in new hires & $45.5 \%$ & & $66.2 \%$ & \\
\hline $\begin{array}{l}\text { Employee representation on the board of } \\
\text { directors }\end{array}$ & $27.3 \%$ & & $32.3 \%$ & \\
\hline El index-sum of above & 1.55 & $(0.93)$ & 1.85 & $(0.96)$ \\
\hline \multicolumn{5}{|c|}{ METHODS TO SHARE INFORMATION WITH EMPLOYEES } \\
\hline Newsletter & $72.7 \%$ & & $88.3 \%$ & \\
\hline Memos & $63.6 \%$ & & $79.9 \%$ & \\
\hline Email & $63.6 \%$ & & $75.6 \%$ & \\
\hline Intranet & $27.3 \%$ & & $39.0 \%$ & \\
\hline Bulletin board & $81.8 \%$ & & $87.1 \%$ & \\
\hline Regular meetings at dept./workgroup level & $90.9 \%$ & & $96.7 \%$ & \\
\hline Regular meetings at company level & $63.6 \%$ & & $74.6 \%$ & \\
\hline Centralized file of policies/procedures & $63.6 \%$ & & $77.7 \%$ & \\
\hline New employee orientation & $90.9 \%$ & & $96.5 \%$ & \\
\hline Information index-sum of above & 6.18 & (2.09) & 7.15 & $(2.02)$ \\
\hline \multicolumn{5}{|l|}{ OTHER POLICIES } \\
\hline 401(k) plan & $90.9 \%$ & & $94.7 \%$ & \\
\hline Other pension & $27.3 \%$ & & $55.9 \%$ & \\
\hline Formal grievance procedure & $54.5 \%$ & & $70.7 \%$ & \\
\hline Labor-management training & $45.5 \%$ & & $66.2 \%$ & \\
\hline Employee surveys & $63.6 \%$ & & $74.2 \%$ & \\
\hline Any bonuses & $90.9 \%$ & & $96.5 \%$ & \\
\hline Bonuses based on indiv. performance & $45.5 \%$ & & $30.5 \%$ & \\
\hline Suggestion system & $27.3 \%$ & & $36.1 \%$ & \\
\hline \multicolumn{5}{|l|}{ ESOP VARIABLES } \\
\hline Pct. of pay contributed to plan-mean & $9.8 \%$ & $(5.5 \%)$ & $10.6 \%$ & $(4.2 \%)$ \\
\hline Pct. of company owned by ESOP & $54.2 \%$ & $(27.2 \%)$ & $51.3 \%$ & $(21.9 \%)$ \\
\hline Average ESOP value per employee & $\$ 41,988$ & $(\$ 62,238)$ & $\$ 31,853$ & $(\$ 53,200)$ \\
\hline 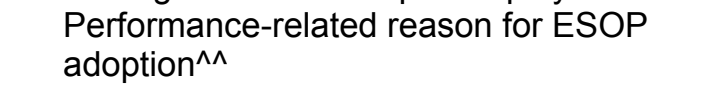 & $63.6 \%$ & & $76.1 \%$ & \\
\hline$H R$ INDEX $X^{\wedge \wedge \wedge}$ & 3.55 & $(1.97)$ & 4.82 & (2.33) \\
\hline
\end{tabular}

$\wedge$ Column 3 represents the percent of employees who are in firms with these policies (not all of whom may actually be covered by the policy).

$\wedge \wedge$ A motivation for the ESOP was "To encourage employees to think like owners,"

"To improve productivity," and/or "To retain or recruit employees."

$\wedge \wedge \wedge$ The HR index adds one point each for: 1) above median on El index, 2) above median on information index, 3) above median on pct. of pay contributed to ESOP, 4) other pension, 5) grievance procedure, 6) labor-management training, and 7) employee surveys. 
TABLE 3: Predicting Employee-Reported Performance with HR Variables

\begin{tabular}{|c|c|c|c|c|c|c|c|c|c|c|c|c|c|c|c|c|}
\hline \multirow{2}{*}{$\begin{array}{l}\text { Dependent variables: } \\
\text { Independent variables }\end{array}$} & \multicolumn{6}{|c|}{ "People at OurCo work hard" } & \multicolumn{5}{|c|}{ Performance index 1} & \multicolumn{5}{|c|}{ Performance index 2} \\
\hline & $(1)$ & & $(2)$ & & $(3)$ & & $(4)$ & & (5) & (6) & & $(7)$ & & (8) & (9) & \\
\hline HR index & $\begin{array}{r}0.119 \\
(0.032)\end{array}$ & * & $\begin{array}{r}0.117 \\
(0.037)\end{array}$ & * & $\begin{array}{r}0.118 \\
(0.037)\end{array}$ & * & $\begin{array}{r}0.452 \\
(0.159)\end{array}$ & * & $\begin{array}{r}0.451 \\
(0.180)\end{array}$ & $\begin{array}{r}\text { * } \\
\quad 0.452 \\
(0.159)\end{array}$ & * & $\begin{array}{r}0.613 \\
(0.282)\end{array}$ & * & $\begin{array}{r}0.517 \\
(0.399)\end{array}$ & $\begin{array}{r}0.551 \\
(0.306)\end{array}$ & \\
\hline $\begin{array}{l}\text { Bonuses based on } \\
\text { indiv. performance }\end{array}$ & $\begin{array}{r}0.597 \\
(0.275)\end{array}$ & * & $\begin{array}{r}0.619 \\
(0.308)\end{array}$ & & $\begin{array}{r}0.592 \\
(0.318)\end{array}$ & & $\begin{array}{r}2.052 \\
(1.074)\end{array}$ & & $\begin{array}{r}2.060 \\
(1.068)\end{array}$ & $\begin{array}{r}1.937 \\
(1.058)\end{array}$ & & $\begin{array}{r}6.166 \\
(1.657)\end{array}$ & * & $\begin{array}{r}6.832 \\
(1.328)\end{array}$ & $\begin{array}{r}6.597 \\
(1.030\end{array}$ & * \\
\hline Suggestion system & $\begin{array}{r}-0.340 \\
(0.167)\end{array}$ & * & $\begin{array}{r}-0.335 \\
(0.159)\end{array}$ & * & $\begin{array}{r}-0.343 \\
(0.168)\end{array}$ & & $\begin{array}{l}-2.015 \\
(0.752)\end{array}$ & * & $\begin{array}{r}-2.013 \\
(0.716)\end{array}$ & $\begin{array}{r}-2.025 \\
(0.661)\end{array}$ & * & $\begin{array}{l}-3.655 \\
(0.293)\end{array}$ & * & $\begin{array}{l}-3.683 \\
(0.278)\end{array}$ & $\begin{array}{r}-3.559 \\
(0.214)\end{array}$ & * \\
\hline $\begin{array}{l}\text { Pct. of company } \\
\text { owned by ESOP }\end{array}$ & $\begin{array}{r}0.369 \\
(0.661)\end{array}$ & & $\begin{array}{r}0.536 \\
(0.851)\end{array}$ & & $\begin{array}{r}0.215 \\
(0.868)\end{array}$ & & $\begin{array}{r}1.600 \\
(2.038)\end{array}$ & & $\begin{array}{r}1.661 \\
(3.724)\end{array}$ & $\begin{array}{r}0.032 \\
(3.389)\end{array}$ & & $\begin{array}{r}0.052 \\
(2.456)\end{array}$ & & $\begin{array}{r}3.058 \\
(4.848)\end{array}$ & $\begin{array}{r}1.032 \\
(3.601)\end{array}$ & \\
\hline $\begin{array}{l}\text { Performance-related } \\
\text { reason for ESOP } \\
\text { adoption }\end{array}$ & & & $\begin{array}{r}0.113 \\
(0.448)\end{array}$ & & $\begin{array}{r}0.004 \\
(0.428)\end{array}$ & & & & $\begin{array}{r}0.041 \\
(1.985)\end{array}$ & $\begin{array}{r}-.439 \\
(1.782)\end{array}$ & & & & $\begin{array}{l}2.8385 \\
(3.306)\end{array}$ & $\begin{array}{r}1.525 \\
(2.436)\end{array}$ & \\
\hline Sense of ownership & & & & & $\begin{array}{r}0.098 \\
(0.030)\end{array}$ & 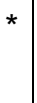 & & & & $\begin{array}{r}0.648 \\
(0.124)\end{array}$ & * & & & & $\begin{array}{r}0.896 \\
(0.197)\end{array}$ & * \\
\hline Constant & $\begin{array}{r}4.836 \\
(0.381)\end{array}$ & * & $\begin{array}{r}4.666 \\
(0.567)\end{array}$ & * & $\begin{array}{r}4.481 \\
(0.564)\end{array}$ & * & $\begin{array}{l}17.906 \\
(1.574)\end{array}$ & * & $\begin{array}{l}17.845 \\
(2.735)\end{array}$ & $\begin{array}{l}16.132 \\
(2.506)\end{array}$ & * & $\begin{array}{l}27.476 \\
(2.018)\end{array}$ & * & $\begin{array}{l}24.040 \\
(3.918)\end{array}$ & $\begin{array}{l}21.974 \\
(3.048)\end{array}$ & * \\
\hline $\begin{array}{l}\text { R-squared } \\
n\end{array}$ & $\begin{array}{r}0.043 \\
2139 \\
\end{array}$ & & $\begin{array}{r}0.043 \\
2139 \\
\end{array}$ & & $\begin{array}{r}0.066 \\
2139 \\
\end{array}$ & & $\begin{array}{r}0.080 \\
2139 \\
\end{array}$ & & $\begin{array}{r}0.080 \\
2139 \\
\end{array}$ & $\begin{array}{l}0.178 \\
2139\end{array}$ & & $\begin{array}{r}0.138 \\
1686 \\
\end{array}$ & & $\begin{array}{r}0.145 \\
1686 \\
\end{array}$ & $\begin{array}{l}0.234 \\
1686 \\
\end{array}$ & \\
\hline
\end{tabular}

* Significantly different from zero at $p<.05$.

Standard errors in parentheses

See Tables 1 and 2 for descriptive statistics. 
TABLE 4: Predicting Other Workplace Outcomes

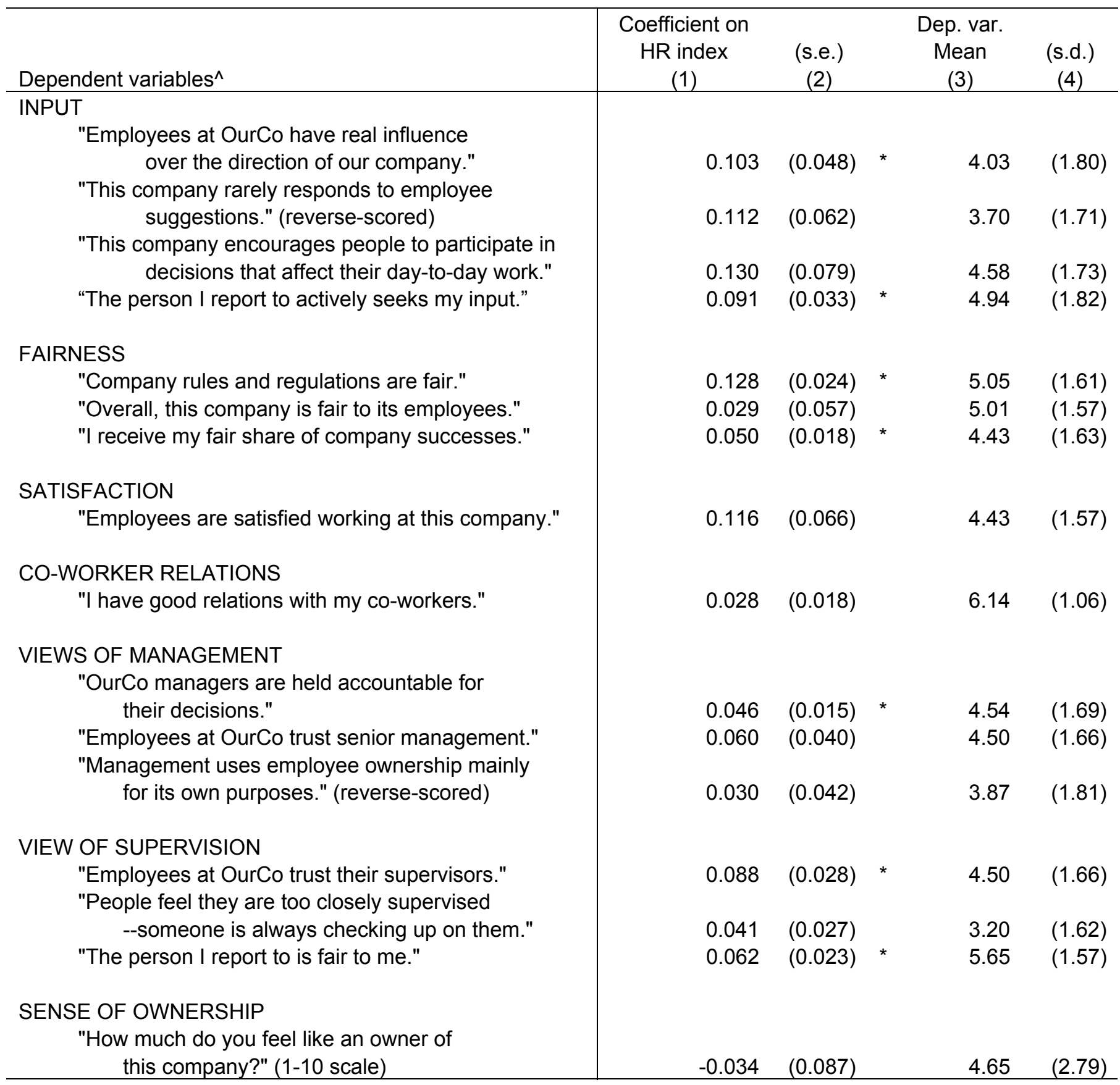

* Significantly different from zero at $\mathrm{p}<.05$

$\wedge$ All dependent variables are measured on 1-7 scale, except as noted.

All regressions include suggestion systems, bonuses based on individual performance, and percent of company owned by ESOP as predictors. See Table 2 for definition and descriptive statistics for HR index. 
TABLE 5: Descriptive Statistics for Within-Company Comparisons

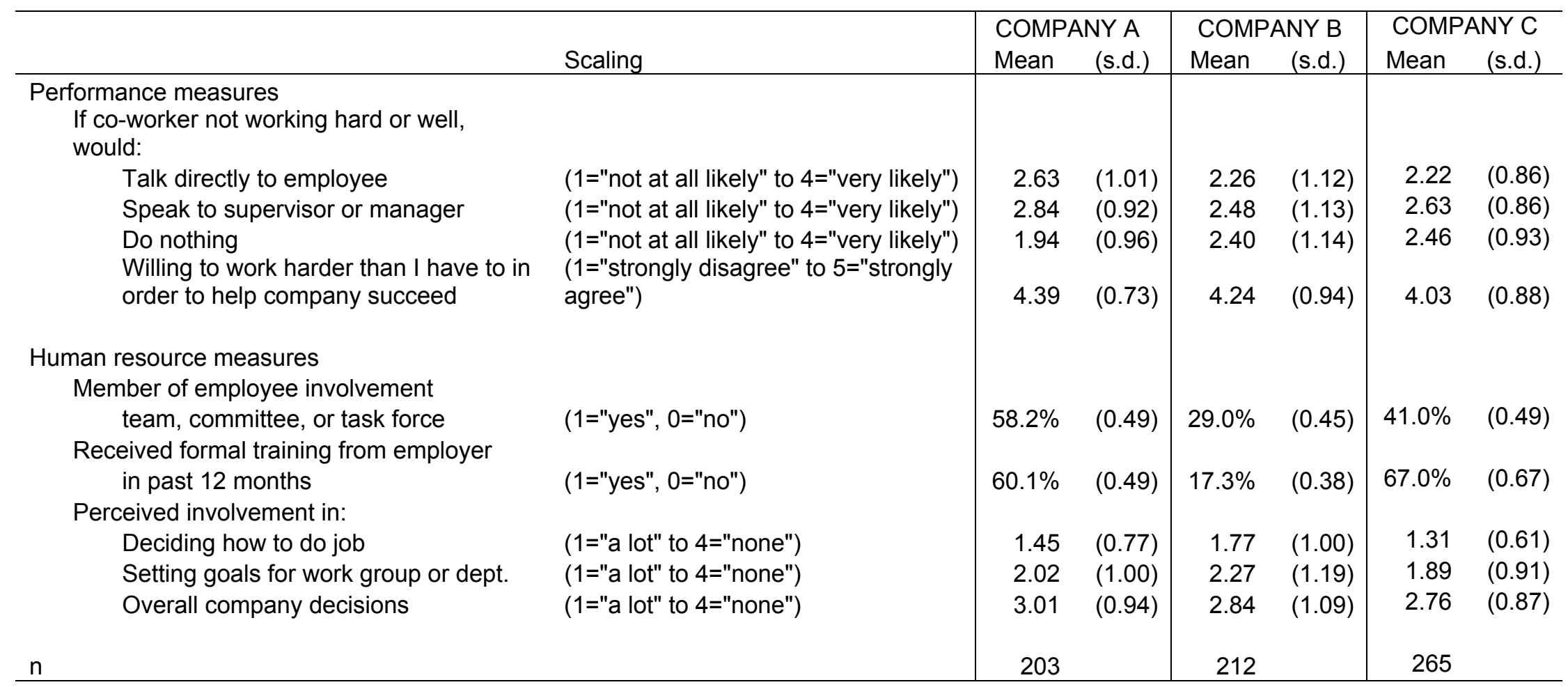


TABLE 6: Within-company Comparisons: Peer Pressure and Worker Effort by Employee Involvement and Training

Figures represent average scores on performance measures, broken down by scores on EI or training.

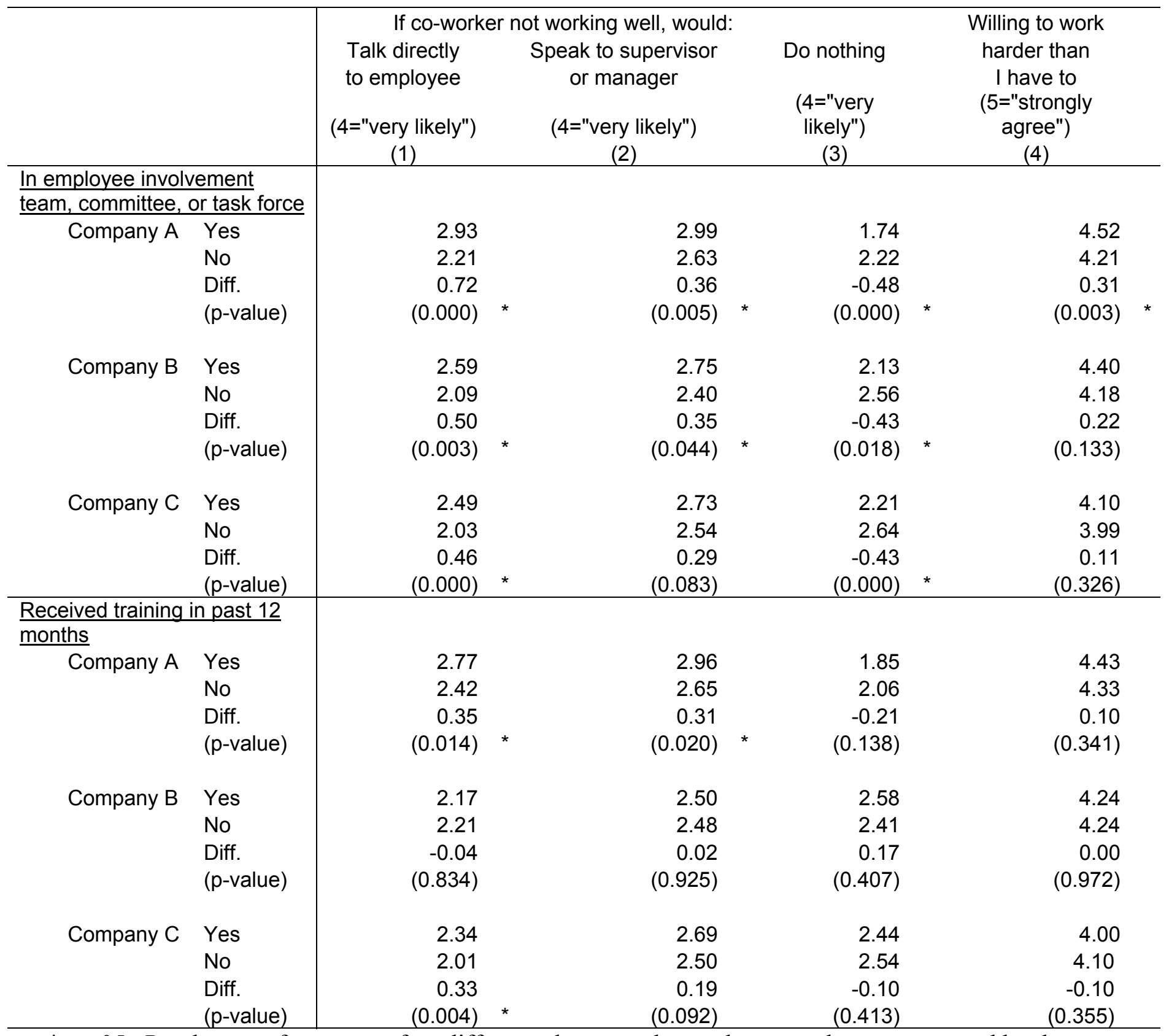

$* \mathrm{p}<.05 \quad \mathrm{P}$-values are from tests of no difference between those who are and are not covered by the practice.

Descriptive statistics in Table 5. 
TABLE 7: Within-company Comparisons: Peer Pressure by Perceived Involvement

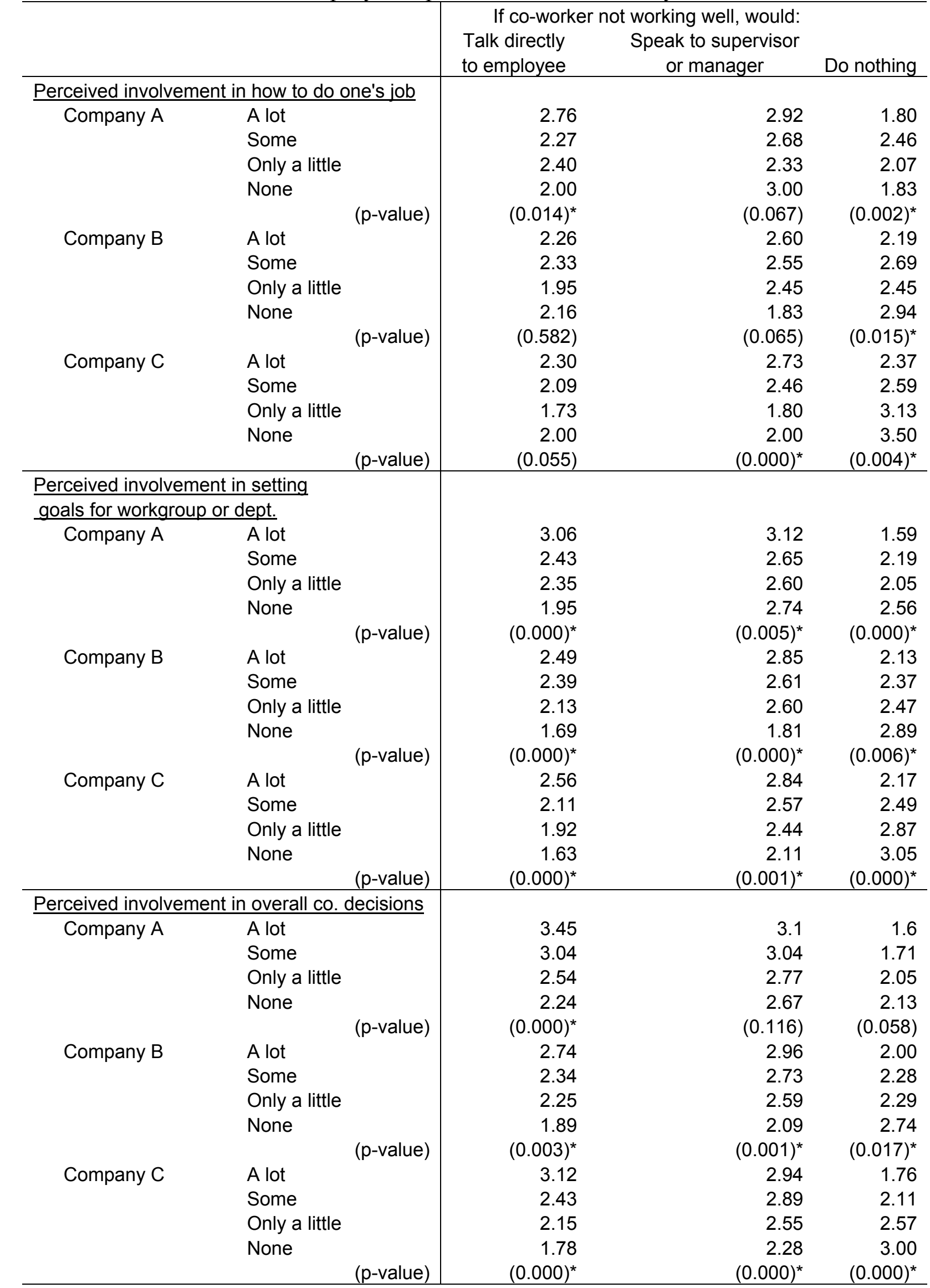

${ }^{*} p<.05 \quad P$-values are from F-tests of no difference among the categories of perceived involvement. 
TABLE 8: Peer Pressure by Perceived Involvement Among a National Sample of Employee-owners

Figures represent average scores on how one would respond to shirking co-worker, broken down by participation measures.

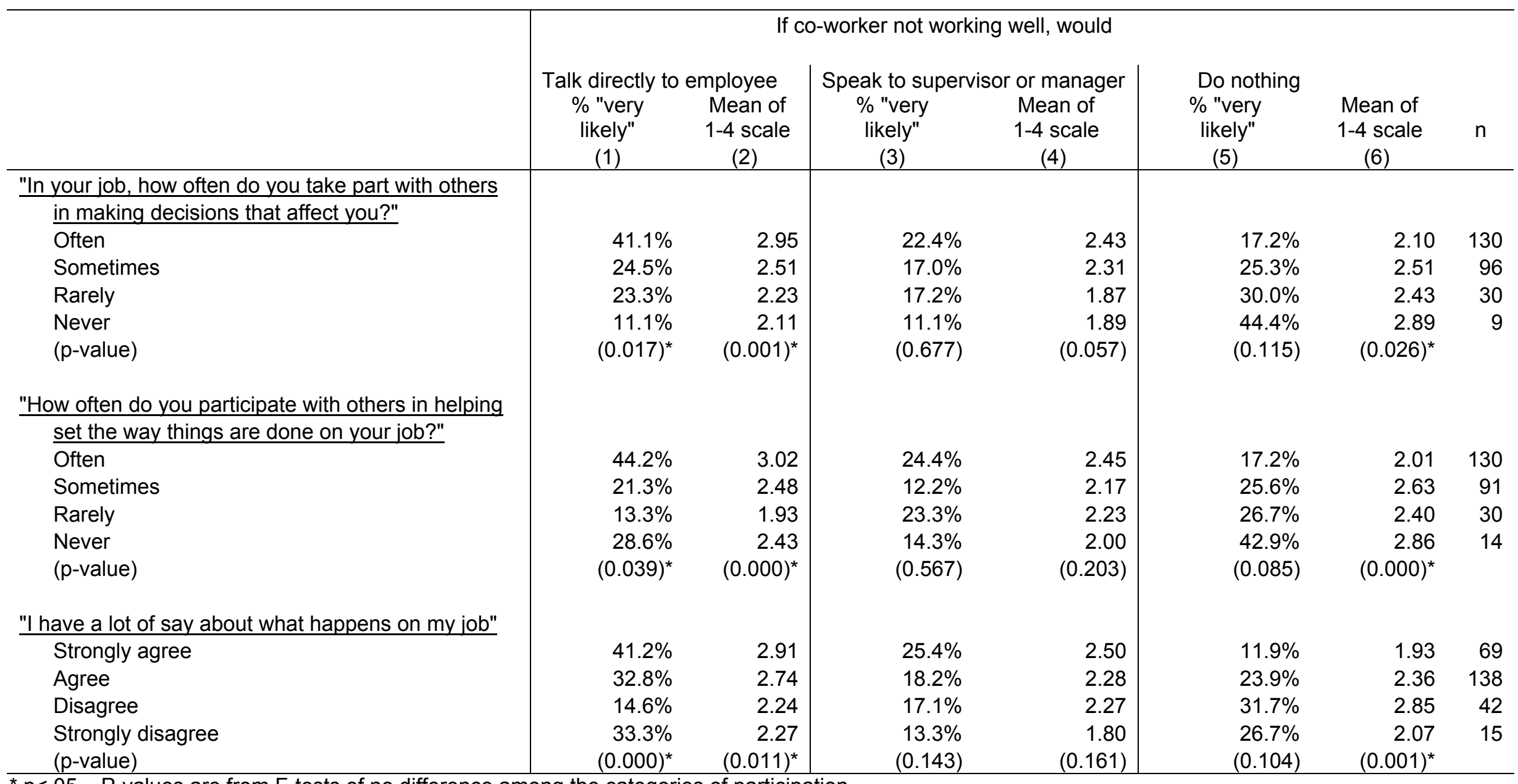

${ }^{*} p<.05 \quad P$-values are from F-tests of no difference among the categories of participation.

Source: 2002 General Social Survey data 